\title{
Editorial
}

\section{Além do "cerimonialismo" das estratégias de internacionalização}

\section{Alketa Peci 1}

1 Fundação Getulio Vargas / Escola Brasileira de Administração Pública e de Empresas, Rio de Janeiro / RJ - Brasil

Neste ano comemora-se o aniversário de 60 anos da Revista de Administração de Empresas (RAE). Pioneira na área de Administração, deu início, junto com revistas como a própria Revista de Administração Pública (RAP) ou a Revista de Administração (São Paulo) [RAUSP], à produção cientifica do campo de Administração - instaurando um marco nesse sentido - por várias décadas. Hoje, sessenta anos depois da criação da RAE, existem mais de 300 revistas acadêmicas no campo de Administração (Rosa \& Romani-Dias, 2019b). A trajetória desta revista sessentona destaca-se pela capacidade de inovar e moldar os rumos do conhecimento em Administração, construindo sua reputação como uma das principais revistas desta área no país.

Demonstrei, em artigo recém-publicado em coautoria com Lilian Alfaia Monteiro, na edição comemorativa dos 60 anos da RAE, que as revistas acadêmicas são, juntamente com pesquisadores, programas acadêmicos, reguladores e financiadores (a exemplo da Capes e $\mathrm{CNPq}$ ), atores muito importantes na produção e evolução do conhecimento científico (Peci \& Monteiro, 2021). De fato, as revistas, como principais meios de veiculação e comunicação da contribuição científica, desempenham um papel-chave na dinâmica competitiva do campo científico, uma vez que são ranqueadas e ajudam a "ranquear" pesquisadores e programas, promovendo a lógica de competição inerente ao jogo. No contexto brasileiro, esse papel é estimulado pela competição promovida pelos reguladores e financiadores como CAPES e CNPq, que impõem a lógica de rankings a programas, pesquisadores individuais e revistas acadêmicas.

O ranking é baseado em várias métricas que diferenciam as revistas, dentre as quais, atualmente, destaca-se "a internacionalização". Conforme demonstrado por Rosa e Romani-Dias (2019a, 2019b), a internacionalização é compreendida e materializada de diversas formas pelas revistas brasileiras. Quase 60\% das revistas dos estratos Qualis (A2) mais elevados adotam publicações bilíngue ou em inglês; do estrato B1, 73,33\% dos periódicos também optam por esse tipo de publicação; e do B5, $100 \%$ dos periódicos publicam exclusivamente em português. Entretanto, os autores observam que boa parte das revistas nacionais não atinge presença significativa nos principais indexadores nacionais (SciELO) e internacionais (Scopus, Web of Science, entre outros) e ainda apresentam métricas de baixo impacto em comparação com pares internacionais, indicando certo risco de adotar de forma "cerimonial" estratégias de internacionalização.

A estratégia de internacionalização da RAP abrange várias dessas dimensões. A opção por uma estratégia de publicação bilíngue elevou o número de submissões internacionais a 366 (trezentos 
e sessenta e seis) de 2015 a 2020, ao passo que as submissões nacionais mantiveram o ritmo de crescimento: ultrapassamos 700 submissões em 2020. A RAP está bem ranqueada no Scopus (índice H 17, que aumenta anualmente), e já entrou no Emerging Sources Citation Index da Web of Science.

Gostaria de destacar a posição de destaque da RAP no H Scholar, juntamente com as revistas com longa trajetória histórica, como a RAE. O h5 é um índice bibliométrico criado pelo Google, disponibilizado no Google Scholar, e se refere ao indexador h dos artigos publicados nos últimos cinco anos. O índice h5 reflete o maior número h de uma publicação, em que h artigos publicados em um período de 5 anos tenham sido citados no mínimo h vezes cada. A RAP aparece no respeitável $18^{\circ}$ lugar do ranking em português, com um índice h5 de 23 e mediana 35, sendo posicionada como a primeira da área de Administração. Em termos comparativos, a RAP não se distancia de revistas internacionais publicadas na língua inglesa.

Muito ainda precisa ser feito para que a "internacionalização" deixe de ser uma estratégia apenas "cerimonial" e passe a representar a contribuição da ciência brasileira no contexto global. Isso demanda a ação coletiva de várias revistas brasileiras e estratégias de colaboração, indo além da competição de curto prazo e da regulamentação de natureza procedimental que domina o campo atualmente. Os exemplos de outras áreas de conhecimento no Brasil, como a Saúde Pública, assim como boas práticas internacionais fora do eixo anglo-saxônico podem orientar os debates e a formulação de novas estratégias.

Destaco que este número da RAP reúne onze artigos que nos brindam com análises sobre temas relevantes de Administração Pública. O número abre com a contribuição dos professores Carlos Ivan Simonsen Leal e Paulo Figueiredo sobre os desafios da inovação tecnológica no Brasil. Seguem análises importantes sobre as parcerias público-privadas, os discursos mediáticos sobre a privatização e a recuperação pós-desastre em um país emergente. Outros estudos importantes focam as principais estratégias de captura regulatória e suas respectivas formas de mensuração, identificam as culturas de desperdício público, oferecem leituras históricas de uma política pública e analisam a ascensão da renda básica emergencial como alternativa viável de política pública no cenário brasileiro. Por fim, os três últimos trabalhos avaliam a relação entre o ciclo eleitoral e a prática de gerenciamento de resultados nos municípios brasileiros, discutem a crise fiscal dos estados, com foco no Rio de Janeiro, o Regime de Recuperação Fiscal e analisam a relação entre receitas de financiamento e o desempenho e sucesso eleitoral de candidaturas a vereador, confirmando uma forte associação entre dinheiro, voto e sucesso eleitoral.

Desejamos a todos uma boa leitura!

\author{
Alketa Peci \\ Editora-chefe
}




\section{REFERÊNCIAS}

Peci, A., \& Monteiro, L. A. (2021). Revistas acadêmicas como agentes do campo científico de administração. RAE-Revista de Administração de Empresas, 61(3), 1-15. Recuperado de http://dx.doi. org/10.1590/S0034-759020210306

Rosa, R., \& Romani-Dias, M. (2019a). A Presença e o Impacto de Periódicos Brasileiros da Área de Administração, Contabilidade e Turismo em
Bases Científicas. Revista Eletrônica de Ciência Administrativa, 18(3), 327-348. Recuperado de https://doi.org/10.21529/RECADM.2019014

Rosa, R., \& Romani-Dias, M. (2019b). Indexação de Periódicos e a Política de Avaliação Científica: uma análise do campo de administração, contabilidade e turismo no Brasil. Journal of Profess. Bus. Review, 4(2), 1-17. Recuperado de http://dx.doi.org/10.26668/ businessreview/2019.v4i2.168

\section{Alketa Peci}

https://orcid.org/0000-0002-0488-1744

Doutora em Administração; Professora associada da Escola Brasileira de Administração Pública e de Empresas da Fundação Getulio Vargas (FGV EBAPE); Editora-chefe da Revista de Administração Pública (RAP).

E-mail: alketa.peci@fgv.br 